\title{
VOICE AND BARGAINING POWER
}

\author{
HANS GERSBACH \\ HANS HALLER
}

CESIFO WORKING PAPER NO. 1668

CATEgory 2: Public CHOICE

FEBRUARY 2006

An electronic version of the paper may be downloaded

- from the SSRN website:

www.SSRN.com

- from the CESifo website: www.CESifo-group.de 


\title{
VoICE AND BARGAINING POWER
}

\begin{abstract}
We propose a formal concept of the power of voice in the context of a simple model where individuals form groups and trade in competitive markets. Individuals use outside options in two different ways. Actual outside options reflect the possibility to exit or to join other existing groups. Hypothetical outside options refer to hypothetical groups that are ultimately not formed. Articulation of hypothetical outside options in the bargaining process determines the relative bargaining power of the members of a group, which constitutes an instance of the power of voice. The adopted equilibrium concept endogenizes the outside options as well as the power of voice. In our illustrative example, there exists an equilibrium that uniquely determines the power of voice and the allocation of commodities.
\end{abstract}

JEL Code: D5, D13, D71.

Keywords: Power of Voice, competitive equilibria, group formation, bargaining, articulation of outside options.

\author{
Hans Gersbach \\ Alfred-Weber-Institute \\ University of Heidelberg \\ Grabengasse 14 \\ 69117 Heidelberg \\ Germany \\ gersbach@uni-hd.de
}

\author{
Hans Haller \\ Department of Economics \\ Virginia Polytechnic Institute and \\ State University \\ 3021 Pamplin Hall \\ Blacksburg, VA 24061-0316 \\ USA \\ haller@vt.edu
}

January 30, 2006

We thank Clive Bell, Jürgen Eichberger, Theresa Fahrenberger, Ani Guerdjikova and seminar participants in Heidelberg and Vienna for helpful comments. 


\section{Introduction}

Power has always been a prominent theme in the social sciences. The meaning of power can include everything from the ability to keep oneself alive to the ability of government to arrest people. A central conception of power is an individual's capacity to influence decisions taken by a group he or she belongs to.

The influential work of Hirschman (1970) has provided a convenient way of thinking about the power pertaining to collective decisions of social organizations. He distinguishes between power derived from the exit option and power based on voice. Although these concepts have been applied widely, the role of voice has proven extremely difficult to conceptualize. In particular, it is difficult to explain why voice — which may be merely cheap talk — would have any impact on material collective decisions.

In this paper we propose a concept of voice power. ${ }^{1}$ The essential idea is as follows. In a society individuals use outside options in two different ways. First, the possibility to exit or to join other existing groups determines the actual outside options. Second, individuals also reason with reference to hypothetical groups, whose formation would require that more than one individual break away from their existing groups and form a new group. The possibility to form hypothetical, new groups is articulated in the bargaining process. The best possible hypothetical scenario for each person determines the relative bargaining power in existing groups. This impact of articulating one's conceivable opportunities in hypothetical groups is called the "power of voice". We show in a simple model with four individuals that there exists an equilibrium that uniquely determines the allocation of commodities and the power of voice.

Our paper is closely related to the theory of multilateral bargaining problems, when there are potential gains from forming coalitions but there is conflict over which coalition to form and how to distribute gains. The idea of antagonistic outside options

\footnotetext{
${ }^{1}$ Hirschman considers voice as a mechanism of recuperation and a means of influence. Here we focus on the second function.
} 
appears already in Rochford (1984) who focuses on selections from the core. Bennett $(1988,1997)$ has pursued the idea further and has developed an intriguing approach to multilateral bargaining problems. ${ }^{2}$ She considers an agreement within a coalition as a solution for the intra-coalitional bargaining process, if the agreement is consistent with the bargaining processes in all other coalitions. The outside option of an individual is the utility the individual would obtain from the agreement in his best alternative coalition. ${ }^{3}$

Our model shares the one important feature with Bennett (1997) that certain (hypothetical) outside options may not be disagreement outcomes because they are not jointly compatible. Our approach differs in other important aspects from the theory of Bennett $(1988,1997)$. In contrast to her, we consider outside options in a dual role for the bargaining process in a particular coalition. Coalitions belonging to the outcome and, thus, coalitions that will actually form determine outside options in the narrow sense. Hypothetical coalitions, that is those that ultimately are not formed, play a different role. They are used in the speeches of members in a particular coalition in order to articulate potential alternatives. Then the best hypothetical outside alternatives (or maximal complaints) determine the relative bargaining power inside the coalition.

Moreover, the research on group or coalition formation has highlighted that it is ultimately unclear how deviations from a proposed group structure should be modelled. Standard solutions such as Nash stability, individual or coalitional stability ignore any possible further deviations and thus may be myopic and may lack credibility. ${ }^{4}$ Deviations can be followed by further deviations and thus it is plausible to allow a deviating coalition to reason about the ultimate result of its deviation. Such a reasoning

\footnotetext{
${ }^{2}$ Other analyses of multilateral bargaining problems have been proposed by Kalai and Samet (1985), Chatterjee et al. (1993) and Bennett and van Damme (1991). Bell (1991) provides a subtle discussion of the role of power and outside options in rural societies.

${ }^{3}$ The underlying non-cooperative model is an adaptation of the proposal-making model of Selten (1981).

${ }^{4}$ Moreover, in hedonic coalition formation games, the core may be empty. Bogomolnaia and Jackson (2002), Banerjeee et al. (2001), Alcalde and Revilla (2001) and Pápai (2000) provide conditions for the non-emptiness of the core.
} 
of credibility and foresight has been initiated by von Neumann and Morgenstern's (1944) stable set and Harsanyi's (1974) indirect dominance. More recent formalizations of farsightedness and solution concepts include Greenberg (1990), Chwe (1994), Xue (1998), Diamantoudi and Xue (2003), and Barberà and Gerber (2003). They show that the answers depend on the behavioral characteristics of the individuals and that there are various plausible ways to formulate how deviations might induce further deviations. Given these difficulties we assume in the present paper that decision-makers use hypothetical outside options as arguments when they bargain over consumption bundles. The way in which such uncertain outside options impact the bargaining outcome is axiomatized through the "voice impact function" introduced in section 4.

At a more abstract level, our paper suggests a way to formalize how discussion among individuals can bring about a consensus. The role of communication in reaching a consensus in democratic societies has been stressed a great deal in political science (see e.g. Elster 1998) and philosophy (see e.g. Habermas 1987). In our context, discussion enables each side to convince the other of the feasibility of potential best alternatives. Each individual assesses the feasibility of hypothetical outside options of other group members. We assume that this deliberation and discussion transforms the best hypothetical outside alternative of one individual into concessions by the other individual and thus into relative bargaining power.

The paper is organized as follows. In the next section we introduce a simple model that serves as an illustrative example. In section 4 we derive the equilibria with free group formation. Voice is introduced and the equilibria with voice are derived in section 5. In section 6 we illustrate our findings with a numerical example. Section 7 offers final remarks. 


\section{Basic Feedback Mechanism}

Here we outline the basic feedback mechanism that incorporates the impact of voice. We envision an economy where individuals can form two-person groups that trade in competitive markets. Individuals are denoted by $i$ or $j$. It is assumed that at the prevailing market conditions, person $j$ obtains utility $U_{j}^{0}$ from acting and living as a single. The utility levels $U_{j}^{0}$ are called actual outside options. If individuals 1 and 2 form group $h$, they enjoy respective bargaining power $\beta_{h}$ and $1-\beta_{h}$, say, within the group. Maximization of the Nash product

$$
N_{h}=\left(U_{1}-U_{1}^{0}\right)^{\beta_{h}} \cdot\left(U_{2}-U_{2}^{0}\right)^{1-\beta_{h}}
$$

with respect to feasible utilities $\left(U_{1}, U_{2}\right) \geq\left(U_{1}^{0}, U_{2}^{0}\right)$ yields a solution $\left(U_{1}^{*}, U_{2}^{*}\right)$. We shall continue to focus on the group $h=\{1,2\}$, while an analogous treatment applies to any two-person group that actually forms.

The values $U_{j}^{0}, j \neq 1,2$, also serve as reservation utility levels when individuals 1 or 2 form a hypothetical group with other individuals. These reservation utilities determine hypothetical outside option values $\widehat{U}_{1}$ and $\widehat{U}_{2}$, embodying the best conceivable outcomes that person 1 and 2, respectively, could expect when forming groups with third parties. Assuming $\widehat{U}_{i}>U_{i}^{*}$, the difference $\widehat{U}_{i}-U_{i}^{*}$ constitutes the maximal complaint $i=1,2$ can articulate vis-à-vis her partner. The power of voice manifests itself via the impact of $\widehat{U}_{1}-U_{1}^{*}$ and $\widehat{U}_{2}-U_{2}^{*}$ on the bargaining weight $\beta_{h}$. Namely, we postulate a voice impact function $f: \mathbb{R}_{+} \rightarrow \mathbb{R}_{+}$so that ${ }^{5}$

$$
\beta_{h}=f\left(\frac{\widehat{U}_{1}-U_{1}^{*}}{\widehat{U}_{2}-U_{2}^{*}}\right),
$$

which is tantamount to equation (3) below. Thus given actual outside option values $U_{1}^{0}, U_{2}^{0}, \ldots$ and actual two-person groups $g, h, \ldots$, one obtains a composite mapping $B$ from the tuples of bargaining weights $\left(\beta_{g}, \beta_{h}, \ldots\right)$ to the tuples of bargaining weights. $B$ has the following schematic form:

\footnotetext{
${ }^{5}$ The definition can be extended to the cases $\widehat{U}_{i}<U_{i}^{*}$ by setting $\beta_{h}=1$ if $\widehat{U}_{1}>U_{1}^{*}$ and $\widehat{U}_{2}<U_{2}^{*}$ and $\beta_{h}=\frac{1}{2}$ if $\widehat{U}_{i}<U_{i}^{*}, i=1,2$, etc.
} 


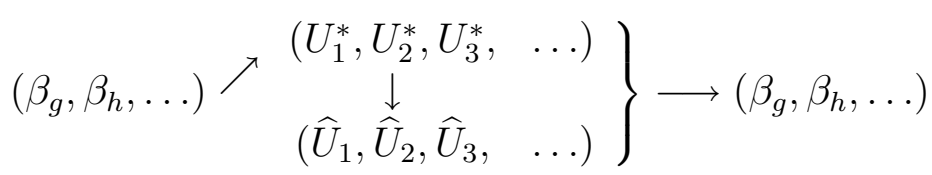

A fixed point of $B$ endogenizes the power of voice.

We envision such a scheme to apply to many socio-economic situations. In the illustrative example below, the maximizer of $N_{h}$ will assume the parametric form $U_{1}^{*}=U_{1}\left(\alpha_{h}\right), U_{2}^{*}=U_{2}\left(\alpha_{h}\right)$ where $\alpha_{h}$ is the weight of individual 1 in the utalitarian welfare function of household $h$ and the fixed point problem will be formulated in terms of the parameter-tuples $\left(\alpha_{g}, \alpha_{h}, \ldots\right)$; see equation (5). Moreover, the economic environment is going to depend on the price system $p$ which in turn is determined by market clearing conditions.

\section{The Model: An Illustrative Example}

In this section, we describe the primitive data of our example. The model is an exchange economy where individuals can form groups in which they benefit from group externalities. Hence, we need to define consumers, group structures, commodities, endowments, allocations, and preferences.

\subsection{Consumer Characteristics and Allocations}

We consider a population of four consumers, represented by the set $I=\{1, \ldots, 4\}$. A generic consumer is again denoted by $i$ or $j$. A population with four individuals proves to be just enough to define and illustrate the concept of power of voice.

The population $I$ is partitioned into groups, i.e. there exists a partition $P$ of $I$ into non-empty subsets. We call any such partition $P$ a group structure in $I$. A generic group is denoted $h, g$ or $k$. We treat the group structure as an object of endogenous choice. Groups are endogenously formed so that some group structure $P$ is ultimately realized. 
We assume that there exist two commodities for private consumption. Each individual $i \in I$ has a consumption set $X_{i}=\mathbb{R}_{+}^{2}$ so that the commodity allocation space is $\mathcal{X} \equiv \prod_{j \in I} X_{j}$. The consumption of individual $i$ is denoted by $x_{i}=\left(x_{i}^{1}, x_{i}^{2}\right)$ or $y_{i}=\left(y_{i}^{1}, y_{i}^{2}\right)$. The consumption allocation is denoted by $\mathbf{x} . \quad \mathcal{X}_{h}=\prod_{i \in h} X_{i}$ is the consumption set for group $h$. $\mathcal{X}_{h}$ has generic elements $\mathbf{x}_{\mathbf{h}}=\left(x_{i}\right)_{i \in h}$.

Preferences are represented by $U_{i}\left(\mathbf{x}_{\mathbf{h}} ; h\right)=U_{i}\left(x_{i}\right)+U_{i}^{G}(h)=U_{i}\left(x_{i}^{1}, x_{i}^{2}\right)+U_{i}^{G}(h)$ where $x_{i}^{k}$ denotes the quantity of good $k(k=1,2)$ consumed by individual $i . U_{i}^{G}(h)$ captures the pure group externality contributing to the utility of individual $i$. Specifically, we assume $\gamma \in(0,1), b>0$ and

$$
U_{i}\left(\mathbf{x}_{\mathbf{h}} ; h\right)= \begin{cases}\gamma \ln x_{i}^{1}+(1-\gamma) \ln x_{i}^{2}, & \text { in case } h=\{i\} ; \\ \gamma \ln x_{i}^{1}+(1-\gamma) \ln x_{i}^{2}+v_{i j}, & \text { in case } h=\{i, j\} \quad \text { with } \quad v_{i j} \geq 0, i \neq j ; \\ \gamma \ln x_{i}^{1}+(1-\gamma) \ln x_{i}^{2}-b, & \text { in case } \# h=3 ; \\ \gamma \ln x_{i}^{1}+(1-\gamma) \ln x_{i}^{2}-b, & \text { in case } \# h=4 .\end{cases}
$$

Note that we adopt the assumption in Gersbach and Haller (2003) that an individual does not care about the features of an allocation beyond the boundaries of his own group. If a particular group structure is given, he is indifferent about the affiliation and consumption of individuals not belonging to his own group. Note that forming a threeperson or four-person group exerts negative group externalities of $-G$ on everybody. Hence, such groups will never be formed in equilibrium.

We further assume individual endowments $w_{i}=\left(w_{i}^{1}, w_{i}^{2}\right)$. For a potential group $h$, its endowment is the commodity bundle $w_{h} \in \mathbb{R}^{2}$ given by the sum of the endowments of all participating individuals: $w_{h}=\sum_{i \in h} w_{i}$. The social or aggregate endowment is $w_{S}=\sum_{i \in I} w_{i}$. An allocation is a pair $(\mathbf{x} ; P)$ specifying the consumption bundle and group membership of each consumer. 


\subsection{The Equilibrium Notion}

The notion of voice power will act as a selection device for competitive exchange among groups. Hence, we first need to define an equilibrium notion in which the power of voice can be embedded. Among the several conceivable ways to formulate an equilibrium state of a model with variable group structure, we follow Gersbach and Haller (2003) and employ the concept of a competitive equilibrium with free group formation.

We briefly review the definition for a competitive equilibrium with free group formation. We consider a group $h \in P$ and a price system $p \in \mathbb{R}^{2}$. For $\mathbf{x}_{\mathbf{h}}=\left(x_{i}\right)_{i \in h} \in \mathcal{X}_{h}$,

$$
p * \mathbf{x}_{\mathbf{h}} \equiv p \cdot\left(\sum_{i \in h} x_{i}\right)
$$

denotes the expenditure of group $h$ on group consumption plan $\mathbf{x}_{\mathbf{h}}$ at the price system $p$. As $p$ and $\mathbf{x}_{\mathbf{h}}$ are of different dimension for multi-member groups, we use the *product in lieu of the familiar inner product. Then group $h$ 's budget set is defined as

$$
B_{h}(p)=\left\{\mathbf{x}_{\mathbf{h}} \in \mathcal{X}_{h}: p * \mathbf{x}_{\mathbf{h}} \leq p \cdot w_{h}\right\}
$$

We next define the efficient budget set $E B_{h}(p)$ as the set of $\mathbf{x}_{\mathbf{h}} \in B_{h}(p)$ with the property that there is no $\mathbf{y}_{\mathbf{h}} \in B_{h}(p)$ such that

(i) $U_{i}\left(\mathbf{y}_{\mathbf{h}} ; h\right) \geq U_{i}\left(\mathbf{x}_{\mathbf{h}} ; h\right)$ for all $i \in h$;

(ii) $U_{i}\left(\mathbf{y}_{\mathbf{h}} ; h\right)>U_{i}\left(\mathbf{x}_{\mathbf{h}} ; h\right)$ for some $i \in h$.

Further define a state of the economy as a triple $(p, \mathbf{x} ; P)$ such that $p \in \mathbb{R}^{2}$ is a price system and $(\mathbf{x} ; P) \in \mathcal{X} \times P$ is an allocation, i.e. $\mathbf{x}=\left(x_{i}\right)_{i \in I}$ is an allocation of commodities and $P$ is an allocation of consumers (a group structure, a partition of the population into groups). A state $(p, \mathbf{x} ; P)$ is a competitive equilibrium with free group formation (CEFG) if it satisfies the following conditions: 
1. $\mathbf{x}_{\mathbf{h}} \in E B_{h}(p)$ for all $h \in P$.

2. $\sum_{i} x_{i}=w_{S}$.

3. There is no $h \in P, i \in h$ and $y_{i} \in B_{\{i\}}(p)$ such that

$$
U_{i}\left(y_{i} ;\{i\}\right)>U_{i}\left(\mathbf{x}_{\mathbf{h}} ; h\right)
$$

4. There are no $h$ and $g \in P, i \in h$ and $\mathbf{y}_{\mathbf{g} \cup\{\mathbf{i}\}} \in B_{g \cup\{i\}}(p)$ such that

$$
\begin{aligned}
& U_{j}\left(\mathbf{y}_{\mathbf{g} \cup\{\mathbf{i}\}} ; g \cup\{i\}\right)>U_{j}\left(\mathbf{x}_{\mathbf{g}} ; g\right) \text { for all } j \in g ; \\
& U_{i}\left(\mathbf{y}_{\mathbf{g} \cup\{\mathbf{i}\}} ; g \cup\{i\}\right)>U_{i}\left(\mathbf{x}_{\mathbf{h}} ; h\right) .
\end{aligned}
$$

Condition 1 reflects collective rationality. Efficient choice by the group refers to the individual consumption and welfare of its members, not merely to the aggregate consumption bundle of the group. Condition 2 requires market clearing. Condition 3 stipulates that no individual wants to leave a group and participate as a one-member group in the market at the going equilibrium prices. Condition 4 requires that no individual can leave a group and can propose a feasible consumption allocation to the members of a new group, created by the individual and another already existing group, which makes everybody in the new group better off at the going equilibrium prices.

\section{Equilibria with Free Group Formation}

To prepare a formal treatment of the power of voice, we first characterize equilibria with free group formation (CEFG). We observe that we can neglect group structures where the group size is larger than 2, since forming a four-person or a three-person group exerts negative group externalities on everybody. Accordingly, only group structures with two two-person groups prevail in CEFG.

Commodity prices are normalized so that $p_{1}=1$. We can represent the efficient decisions of a two-person group $h=\{i, j\}, i<j$, by assuming that the group maximizes 
a utilitarian social welfare function

$$
W_{h}=\alpha_{h} U_{i}\left(x_{i}\right)+\left(1-\alpha_{h}\right) U_{j}\left(x_{j}\right)
$$

subject to the budget constraint. The number $\alpha_{h}\left(0 \leq \alpha_{h} \leq 1\right)$ is the utalitarian weight of individual $i$ in household $h$. In this section we treat $\alpha_{h}$ as parametrically given. In section 5 the weight $\alpha_{h}$ will be endogenized. Given any $p_{2}$, identical homothetic preferences with respect to consumption imply that group demand as well as individual consumption bundles will be linear in income. Hence, we immediately obtain

Lemma 1 CEFG exist and have the following properties:

(i) Two two-person groups are formed.

(ii) The equilibrium price $p_{2}^{*}$ is given by $p_{2}^{*}=(1-\gamma) \cdot w_{S}^{1} /\left[\gamma \cdot w_{S}^{2}\right]$, with associated nominal social wealth $y_{S}^{*}=w_{S}^{1}+p_{2}^{*} w_{S}^{2}$ and nominal income $y_{k}^{*}=w_{k}^{1}+p_{2}^{*} w_{k}^{2}$ for any group $k$.

(iii) The equilibrium allocation for a group structure $P$, say $P=\{h, g\}$ with $h=$ $\{1,2\}$ and $g=\{3,4\}$, is characterized by two numbers $\alpha_{h}$ and $\alpha_{g}\left(0<\alpha_{h}<1\right.$, $\left.0<\alpha_{g}<1\right)$ and given by

$$
\begin{aligned}
& x_{1}^{*}=\alpha_{h}\left(y_{h}^{*} / y_{S}^{*}\right) w_{S}, \quad x_{2}^{*}=\left(1-\alpha_{h}\right)\left(y_{h}^{*} / y_{S}^{*}\right) w_{S} \\
& x_{3}^{*}=\alpha_{g}\left(y_{g}^{*} / y_{S}^{*}\right) w_{S}, \quad x_{4}^{*}=\left(1-\alpha_{g}\right)\left(y_{g}^{*} / y_{S}^{*}\right) w_{S} .
\end{aligned}
$$

To establish the boundaries for the numbers $\alpha_{h}$ and $\alpha_{g}$ we observe that we can neglect the joining option. Forming three-person groups does not create positive group externalities for the entrant and destroys existing benefits of group formation. Hence, exit dominates joining in all conceivable deviations from the CEFG candidate.

The exit option for individual $i$ yields utility

$$
U_{i}\left(x_{i}^{0}\left(p_{2}^{*}\right)\right)=\gamma \ln \left(\gamma\left(w_{i}^{1}+p_{2}^{*} w_{i}^{2}\right)\right)+(1-\gamma) \ln \left((1-\gamma)\left(\frac{w_{i}^{1}+p_{2}^{*} w_{i}^{2}}{p_{2}^{*}}\right)\right)
$$

which establishes 


\section{Lemma 2}

For a typical group structure that can qualify for a CEFG, say $P=\{h, g\}$ with $h=$ $\{1,2\}$ and $g=\{3,4\}$, there exist $\underline{\alpha}_{h}<\bar{\alpha}_{h}$ and $\underline{\alpha}_{g}<\bar{\alpha}_{g}$ such that a CEFG with the properties described in lemma 1 exists if and only if

$$
\underline{\alpha}_{h} \leq \alpha_{h} \leq \bar{\alpha}_{h} \text { and } \underline{\alpha}_{g} \leq \alpha_{g} \leq \bar{\alpha}_{g} .
$$

\section{Voice Power}

\subsection{The Concept}

The remaining question is how $\alpha_{h}$ and $\alpha_{g}$ are determined. For that purpose we introduce voice in the following sense: Every group member expresses the utility that he could achieve in a hypothetical group, i.e. in a group that does not currently exist and cannot be formed by exit or by joining another group. The potential gains relative to current utility that group members can identify in their speeches will then determine relative bargaining power through the power of voice.

To formulate the notion of voice power we start with the bargaining problem in a particular group. We assume that a group, say $h=\{1,2\}$, maximizes the Nash product

$$
N_{h}=\left\{U_{1}\left(\mathbf{x}_{\mathbf{h}} ; h\right)-U_{1}\left(x_{1}^{0}\left(p_{2}^{*}\right)\right)\right\}^{\beta_{h}} \cdot\left\{U_{2}\left(\mathbf{x}_{\mathbf{h}} ; h\right)-U_{2}\left(x_{2}^{0}\left(p_{2}^{*}\right)\right)\right\}^{1-\beta_{h}} .
$$

To determine the values of $\beta_{h}$ and $\alpha_{h}$ we proceed in two steps. In the first step, we determine the weight $\alpha_{h}$ that maximizes the Nash product for a given value of $\beta_{h}$. In the second step we determine the value of $\beta_{h}$ for a given $\alpha_{h}$ through the power of voice. An equilibrium will be a pair $\left(\alpha_{h}^{*}, \beta_{h}^{*}\right)$ that solves the group bargaining problem and is consistent with voice power.

We start with the first step. To simplify the notation we use the following shortcuts. If $\alpha_{h}$ is the weight of the first member in the actual group $h$ in the utilitarian welfare 
function, we can express the various utilities as follows:

$$
\begin{aligned}
U_{1}\left(\alpha_{h}\right) & :=U_{1}\left(\mathbf{x}_{\mathbf{h}} ; h\right)=\gamma \ln \left\{\alpha_{h} \gamma y_{h}^{*}\right\}+(1-\gamma) \ln \left\{\alpha_{h}(1-\gamma) y_{h}^{*}\right\}+v_{12} \\
U_{2}\left(\alpha_{h}\right) & :=U_{2}\left(\mathbf{x}_{\mathbf{h}} ; h\right)=\gamma \ln \left\{\left(1-\alpha_{h}\right) \gamma y_{h}^{*}\right\}+(1-\gamma) \ln \left\{\left(1-\alpha_{h}\right)(1-\gamma) y_{h}^{*}\right\}+v_{21} \\
U_{1}^{0} & :=U_{1}\left(x_{1}^{0}\left(p_{2}^{*}\right)\right)=\gamma \ln \left\{\gamma y_{1}^{*}\right\}+(1-\gamma) \ln \left\{(1-\gamma) y_{1}^{*}\right\} \\
U_{2}^{0} & :=U_{2}\left(x_{2}^{0}\left(p_{2}^{*}\right)\right)=\gamma \ln \left\{\gamma y_{2}^{*}\right\}+(1-\gamma) \ln \left\{(1-\gamma) y_{2}^{*}\right\}
\end{aligned}
$$

For any given $\beta_{h}$, the bargaining problem is well defined and can be solved for the utilitarian weights. Taking $\ln N_{h}$ and maximizing with respect to $\alpha_{h}$ yields the first-order condition:

$$
\begin{aligned}
\beta_{h} & \frac{1}{U_{1}\left(\alpha_{h}\right)-U_{1}^{0}}\left\{\gamma \frac{1}{\alpha_{h}}+(1-\gamma) \frac{1}{\alpha_{h}}\right\} \\
& -\left(1-\beta_{h}\right) \frac{1}{U_{2}\left(\alpha_{h}\right)-U_{2}^{0}}\left\{\gamma \frac{1}{1-\alpha_{h}}+(1-\gamma) \frac{1}{1-\alpha_{h}}\right\}=0
\end{aligned}
$$

or

$$
\beta_{h} \frac{1}{\left(U_{1}\left(\alpha_{h}\right)-U_{1}^{0}\right) \alpha_{h}}-\left(1-\beta_{h}\right) \frac{1}{\left(U_{2}\left(\alpha_{h}\right)-U_{2}^{0}\right)\left(1-\alpha_{h}\right)}=0
$$

In the second step we determine $\beta_{h}$ as a function of the utilitarian weight $\alpha_{h}$ through the power of voice. First, we need to be precise about the thinking of members in actual groups about allocations in hypothetical groups. We assume that individuals articulate situations in hypothetical groups to which they might belong and in which other members do not want to leave. We assume that $v_{i 3}>v_{i 4}, i=1,2$ and $v_{3 i}>$ $v_{4 i}, i=1,2$. An individual $i=1,2$ can imagine being in a two-person group $\{i, 3\}$ or $\{i, 4\}$. We concentrate on the group $k=\{i, 3\}$ since forming a group with individual 3 is the more attractive hypothetical group. If individual $i$ imagines a group allocation such that individual 3 obtains his utility as a single, the maximal hypothetical utility for individual $i$, denoted by $\widehat{U}_{i}$, is determined by the system of equations

$$
\begin{aligned}
\widehat{U}_{i} & =\gamma \ln \left\{\gamma \bar{\alpha}_{k}\left(w_{i}^{1}+w_{3}^{1}+p_{2}^{*}\left(w_{i}^{2}+w_{3}^{2}\right)\right)\right\} \\
& +(1-\gamma) \ln \left\{(1-\gamma) \bar{\alpha}_{k}\left(\frac{w_{i}^{1}+w_{3}^{1}+p_{2}^{*}\left(w_{i}^{2}+w_{3}^{2}\right)}{p_{2}^{*}}\right)\right\}+v_{i 3}
\end{aligned}
$$




$$
\begin{aligned}
U_{3}\left(x_{3}^{0}\left(p_{2}^{*}\right)\right) & =\gamma \ln \left\{\gamma\left(1-\bar{\alpha}_{k}\right)\left(w_{i}^{1}+w_{3}^{1}+p_{2}^{*}\left(w_{i}^{2}+w_{3}^{2}\right)\right)\right\} \\
& +(1-\gamma) \ln \left\{(1-\gamma)\left(1-\bar{\alpha}_{k}\right)\left(\frac{w_{i}^{1}+w_{3}^{1}+p_{2}^{*}\left(w_{i}^{2}+w_{3}^{2}\right)}{p_{2}^{*}}\right)\right\}+v_{3 i} .
\end{aligned}
$$

Note that $\bar{\alpha}_{k}$ is the highest possible weight individual $i$ can have in household $k$ without forcing the exit of individual 3. It is obvious that $\bar{\alpha}_{k}$ and $\widehat{U}_{i}$ are uniquely determined. Running through the same exercise for group $g=\{3,4\}$, when individuals imagine forming groups with the first individual, yields imagined utilities $\widehat{U}_{i}, i=3,4$.

We assume that the utilities $\widehat{U}_{i}$ are used in the speeches of existing groups to express their members' aspirations and we further assume that these aspirations translate into relative bargaining power in existing groups. Hence, the relative bargaining power must be consistent with the potential utility gains that individuals can articulate for hypothetical groups. For that purpose we introduce the voice impact function $f: \mathbb{R}_{+} \rightarrow \mathbb{R}_{+}$which can be applied to groups $h$ and $g$. We define the voice impact function by using group $h$. The difference $\widehat{U}_{i}-U_{i}\left(\alpha_{h}\right)$ compares individual $i$ 's maximal aspiration with the status quo. In a sense, the difference constitutes the (maximal) complaint $i$ can articulate about his treatment in the status quo. We postulate that the first consumer's bargaining power in group $h$ depends on the relative complaints via the voice impact function:

$$
\beta_{h}=f\left(\frac{\widehat{U}_{1}-U_{1}\left(\alpha_{h}\right)}{\widehat{U}_{2}-U_{2}\left(\alpha_{h}\right)}\right)
$$

The voice impact function is assumed to satisfy the following requirements:

\section{Properties of the Voice Impact Function}

(1) $f(0)=0$

(2) $f(x)+f(1 / x)=1$

(3) $\lim _{x \rightarrow \infty} f(x)=1$

(4) $f^{\prime}>0$ 
The condition $f(x)+f(1 / x)=1$ supposes that both group members are equally able in transforming hypothetical but possible utility gains from forming other groups into bargaining power through articulation of their aspirations or complaints.

\subsection{Equilibria}

To satisfy all four axioms, we specify the voice impact function as $f(x)=x /(x+1)$. Applying the voice impact function (3) to group $h$ amounts to

$$
\left.\begin{array}{rl}
\beta_{h} & =\frac{\widehat{U}_{1}-U_{1}\left(\alpha_{h}\right)}{\widehat{U}_{1}-U_{1}\left(\alpha_{h}\right)+\widehat{U}_{2}-U_{2}\left(\alpha_{h}\right)} ; \\
1-\beta_{h} & =\frac{\widehat{U}_{2}-U_{2}\left(\alpha_{h}\right)}{\widehat{U}_{1}-U_{1}\left(\alpha_{h}\right)+\widehat{U}_{2}-U_{2}\left(\alpha_{h}\right)} \cdot
\end{array}\right\}
$$

Assuming that there exists a pair $\left(\alpha_{h}, \beta_{h}\right)$ with $0 \leq \alpha_{h} \leq 1,0 \leq \beta_{h} \leq 1$ that satisfies the above equations and inserting the voice power associated with $\beta_{h}$ and $1-\beta_{h}$ into the group optimization rule (given by equation (2)) yields:

$$
\frac{\widehat{U}_{1}-U_{1}\left(\alpha_{h}\right)}{\left(U_{1}\left(\alpha_{h}\right)-U_{1}^{0}\right) \alpha_{h}}=\frac{\widehat{U}_{2}-U_{2}\left(\alpha_{h}\right)}{\left(U_{2}\left(\alpha_{h}\right)-U_{2}^{0}\right)\left(1-\alpha_{h}\right)}
$$

We obtain:

\section{Proposition 1}

Suppose there exists $\alpha_{h} \in\left[\underline{\alpha}_{h}, \bar{\alpha}_{h}\right]$ such that $\widehat{U}_{1}>U_{1}\left(\alpha_{h}\right)$ and $\widehat{U}_{2}>U_{2}\left(\alpha_{h}\right)$. Then there exist unique values $\alpha_{h}^{*} \in(0,1)$ and $\beta_{h}^{*} \in(0,1)$ that solve the group optimization problem and are consistent with voice power. $\alpha_{h}^{*}$ is determined by (5).

The proof of proposition 1 follows immediately from the observation that the left side of (5) is strictly decreasing in $\alpha_{h}$ whereas the right side of (5) is strictly increasing in $\alpha_{h}$. Moreover, for $\alpha_{h} \rightarrow 0\left(1-\alpha_{h} \rightarrow 0\right)$ the left side (right side) becomes infinite. 
Proposition 1 shows how exit and voice power interact in determining the group allocation. Ceteris paribus considerations yield:

\section{Corollary 1}

$$
\frac{\partial \alpha_{h}^{*}}{\partial \widehat{U}_{1}}>0, \quad \frac{\partial \alpha_{h}^{*}}{\partial \widehat{U}_{2}}<0 ; \frac{\partial \alpha_{h}^{*}}{\partial U_{1}^{0}}>0, \quad \frac{\partial \alpha_{h}^{*}}{\partial U_{2}^{0}}<0
$$

We note that exit and voice uniquely determine the group allocation. Given that equilibrium prices are independent of $\alpha_{h}^{*}$ and $\beta_{h}^{*}$ we obtain:

\section{Proposition 2}

Suppose there exist utalitarian weights $\alpha_{h} \in\left[\underline{\alpha}_{h}, \bar{\alpha}_{h}\right]$ and $\alpha_{g} \in\left[\underline{\alpha}_{g}, \bar{\alpha}_{g}\right]$ such that $\widehat{U}_{1}>$ $U_{1}\left(\alpha_{h}\right), \widehat{U}_{2}>U_{2}\left(\alpha_{h}\right), \widehat{U}_{3}>U_{3}\left(\alpha_{g}\right)$, and $\widehat{U}_{4}>U_{4}\left(\alpha_{g}\right)$. Then for $P=\{\{1,2\},\{3,4\}\}$, there exists a unique CEFG of the form $\left(p^{*}, x^{*}, P\right)$ that satisfies the voice power consistency requirement.

\section{Observation 1.}

We chose the above voice impact function $f(x)=x /(1+x)$ for the sake of convenience and transparency. Observe that any voice impact function $f$ is determined by its restriction to $x \in[0,1]$, since $f(x)=1-f(1 / x)$ for $x>1$. Moreover, $f(1)=1 / 2$. Conversely, any differentiable function $f:[0,1] \rightarrow \mathbb{R}_{+}$with $f(0)=0, f(1)=1 / 2$ and $f^{\prime}>0$ can be extended to a voice impact function by setting $f(x)=1-f(1 / x)$ for $x>1$.

\section{Observation 2.}

Suppose all consumers have identical homothetic preferences for consumption, represented by a continuous, concave and weakly increasing utility function which is differentiable, strictly concave and strictly increasing on $\mathbb{R}_{++}^{\ell}$. Then an analogue of lemma 
1 holds. Next consider household $h=\{1,2\}$, say, with voice impact function $f$. Then given $\beta_{h}$ and the equilibrium price system determined in lemma 1, maximization of the Nash product $N_{h}$ yields $\alpha_{h}$ as a continuous function $\varphi_{1}$ of $\beta_{h}$. On the other hand, (3) determines $\beta_{h}$ as a continuous function $\varphi_{2}$ of $\alpha_{h}$. By Brouwer's fixed point theorem, the composition mapping $\varphi_{1} \circ \varphi_{2}$ has a fixed point $\alpha_{h}^{*}$. Hence there exist $\alpha_{h}^{*} \in[0,1]$ and $\beta_{h}^{*} \in[0,1]$ that solve the group optimization problem and are consistent with voice power. The value of $\beta_{h}^{*}$ is obtained via (3). Application of the fixed point theorem does not yield uniqueness and interiority, which falls short of proposition 2.

\section{A Numerical Example}

To illustrate the working of proposition 2 we use the following parameter values:

$$
\gamma=1-\gamma=\frac{1}{2}, \quad w_{1}=w_{2}=w_{3}=w_{4}=(1,1)
$$

Accordingly, $p_{2}^{*}=1$. Moreover,

$$
\begin{aligned}
U_{1}\left(\alpha_{h}\right) & =\frac{1}{2}\left\{\ln \left(2 \alpha_{h}\right)+\ln \left(2 \alpha_{h}\right)\right\}+v_{12}=\ln \left(2 \alpha_{h}\right)+v_{12} \\
U_{2}\left(\alpha_{h}\right) & =\frac{1}{2}\left\{\ln \left[2\left(1-\alpha_{h}\right)\right]+\ln \left[2\left(1-\alpha_{h}\right)\right]\right\}+v_{21}=\ln \left[2\left(1-\alpha_{h}\right)\right]+v_{21} \\
U_{1}^{0} & =\frac{1}{2}\{\ln 1+\ln 1\}=0 \\
U_{2}^{0} & =0 \\
\widehat{U}_{1} & =\frac{1}{2}\left\{\ln \left[2 \bar{\alpha}_{k}\right]+\ln \left[2 \bar{\alpha}_{k}\right]\right\}+v_{13}=\ln \left[2 \bar{\alpha}_{k}\right]+v_{13} \\
U_{3}\left(x_{3}^{0}(1)\right) & =0=\frac{1}{2}\left\{\ln \left(2\left(1-\bar{\alpha}_{k}\right)\right)+\ln \left(2\left(1-\bar{\alpha}_{k}\right)\right)\right\}+v_{31} \\
\widehat{U}_{2} & =\ln \left[2 \bar{\alpha}_{k^{\prime}}\right]+v_{23} \\
U_{3}\left(x_{3}^{0}(1)\right) & =0=\frac{1}{2}\left\{\operatorname { l n } \left(2\left(1-\bar{\alpha}_{k^{\prime}}\right)+\ln \left(2\left(1-\bar{\alpha}_{k^{\prime}}\right)\right\}+v_{32}\right.\right.
\end{aligned}
$$

where $k=\{1,3\}$ and $k^{\prime}=\{2,3\}$. This implies:

$$
\begin{aligned}
2\left(1-\bar{\alpha}_{k}\right)=\mathrm{e}^{-v_{31}}, & \widehat{U}_{1}=\ln \left(2-\mathrm{e}^{-v_{31}}\right)+v_{13} \\
2\left(1-\bar{\alpha}_{k^{\prime}}\right)=\mathrm{e}^{-v_{32}}, & \widehat{U}_{2}=\ln \left(2-\mathrm{e}^{-v_{32}}\right)+v_{23}
\end{aligned}
$$


Using (5), we find that the group allocation satisfies:

$$
\frac{\ln \left(2-\mathrm{e}^{-v_{31}}\right)+v_{13}-\ln \left(2 \alpha_{h}\right)-v_{12}}{\alpha_{h}\left(\ln \left(2 \alpha_{h}\right)+v_{12}\right)}=\frac{\ln \left(2-\mathrm{e}^{-v_{32}}\right)+v_{23}-\ln \left[2\left(1-\alpha_{h}\right)\right]-v_{21}}{\left(1-\alpha_{h}\right)\left(\ln \left[2\left(1-\alpha_{h}\right)\right]+v_{21}\right)}
$$

This equation determines $\alpha_{h}^{*}$. We obtain

Corollary 2 Suppose $v_{12}=v_{21}$. Suppose that there exists $\alpha_{h}$ such $\widehat{U}_{1}>U_{1}\left(\alpha_{h}\right)>0$

and $\widehat{U}_{2}>U_{2}\left(\alpha_{h}\right)>0$. Then there exists a unique value of $\alpha_{h}^{*}$. Moreover, $\alpha_{h}^{*}>\frac{1}{2}$ if and only if

$$
\ln \left(2-e^{-v_{31}}\right)+v_{13}>\ln \left(2-e^{-v_{32}}\right)+v_{23}
$$

Intuitively, the higher $v_{13}$ relative to $v_{23}$ and the higher $v_{31}$ relative to $v_{32}$, the higher the relative bargaining power of the first individual since her power of voice is comparatively larger.

\section{$7 \quad$ Final Remarks}

Via an example we have proposed and examined a concept of voice power. Numerous issues deserve further attention. Apart from incorporating voice power in more general models, a more detailed behavioral foundation of our concept should be taken up in future research. Moreover, here the power of voice relies on cardinal utility specifications since the voice impact function relies on cardinality. However, it would be desirable to have a clear view as to which properties of voice depend on ordinal properties of preferences and which properties depend on the cardinal representation. 


\section{References}

Alcalde, J., and Revilla, P.: "Tops responsiveness, strategy-proofness and coalition formation problems", mimeo, 2001.

Banerjee et al.: "Core in a Simple Coalition Formation Game", Social Choice and Welfare 18 (2001), 135-153.

Barberà, S., and Gerber, A.: "On Coalition Formation: Durable Coalition Structures", Mathematical Social Sciences 45 (2003), 185-203.

Becker, G.S.: "Nobel Lecture: The Economic Way of Looking at Behavior", Journal of Political Economy 101 (1993b), 385-409.

Bell, C: "Markets, Power and Productivity in Rural Asia: a Review Article", Journal of Development Economics (1991), 373-393.

Bennett, E.: "Multilateral Bargaining Problems", Games and Economic Behavior 19 (1997), 151-179.

Bennett, E.: "Consistent Bargaining Conjectures in Marriages and Matching" Journal of Economic Theory 45 (1988), 392-407.

Bennett, E., and van Damme, E.: "Demand Commitment Bargaining: The Case of Apex Games", in Game Equilibrium Models, Vol. III, Strategic Bargaining, (R. Selten, Ed.), (1991), 118-140, Berlin: Springer.

Bogomolnaia, A., Jackson, M.O.: "The Stability of Hedonic Coalition Structures", Games and Economic Behavior 38 (2002), 201-230.

Chatterjee, K., Dutta, B., Ray, D., and Sengupta, K.: "A Non-Cooperative Theory of Coalitional Bargaining", Review of Economic Studies 60 (1993), 463-477.

Chwe, M.S.-Y.: "Farsighted Coalitional Stability", Journal of Economic Theory 63 (1994), 299-325. 
Diamantoudi, E., and Xue, L.: "Farsighted Stability in Hedonic Games", Social Choice and Welfare 21 (2003), 39-61.

Elster, J. (ed.): Deliberative Democracy. Cambridge University Press: Cambridge, UK, 1998.

Gersbach, H., and Haller, H.: "Collective Decisions and Competitive Markets," Review of Economic Studies 68 (2001), 347-368.

Gersbach, H., and Haller, H.: "Competitive Markets, Collective Decisions and Group Formation," Working Paper, 2003.

Greenberg, J.: "The Theory of Social Situations: An Alternative Game-Theoretic Approach", Cambridge University Press: Cambridge, UK, 1990.

Habermas, J.: Theory of Communicative Action. Beacon Press: Boston, 1987.

Harsanyi, J.C.: "An Equilibrium-Point Interpretation of Stable Sets and a Proposed Alternative Definition." Management Science 20 (1974), 1472-1495.

Hirschman, A.O.: Exit, Voice, and Loyalty. Harvard University Press, Cambridge, Massachusetts, 1970.

Kalai, E., and Samet, D.: "Monotonic Solutions to General Competitive Games", Econometrica 53, (1985), 307-327.

von Neumann, J., Morgenstern, O.: "Theory of Games and Economic Behavior", Princeton University Press, Princeton, 1944.

Pápai, S.: "Unique stability in simple coalition formation games", mimeo, 2000.

Rochford, S.C.: "Symmetrical Pairwise-Bargained Allocations in an Assignment Market", Journal of Economic Theory 34, (1984), 262-281. 
Selten, R.: "A Noncooperative Model of Characteristic Function Bargaining", in Essays in Game Theory and Mathematical Economics in Honor of Oskar Morgenstern (V. Boehm and H. Nachtkamp, Eds.), (1981), 131-151. Vienna, Zurich; Wissenschaftsverlag Bibliographisches Institut Mannheim.

Xue, L.: "Coalitional Stability under Perfect Foresight.", in Economic Theory 11 (1998), 603-627. 


\section{CESifo Working Paper Series}

(for full list see www.cesifo-group.de)

1605 Kathleen M. Day and Stanley L. Winer, Policy-induced Internal Migration: An Empirical Investigation of the Canadian Case, November 2005

1606 Paul De Grauwe and Cláudia Costa Storti, Is Monetary Policy in the Eurozone less Effective than in the US?, November 2005

1607 Per Engström and Bertil Holmlund, Worker Absenteeism in Search Equilibrium, November 2005

1608 Daniele Checchi and Cecilia García-Peñalosa, Labour Market Institutions and the Personal Distribution of Income in the OECD, November 2005

1609 Kai A. Konrad and Wolfgang Leininger, The Generalized Stackelberg Equilibrium of the All-Pay Auction with Complete Information, November 2005

1610 Monika Buetler and Federica Teppa, Should you Take a Lump-Sum or Annuitize? Results from Swiss Pension Funds, November 2005

1611 Alexander W. Cappelen, Astri D. Hole, Erik Ø. Sørensen and Bertil Tungodden, The Pluralism of Fairness Ideals: An Experimental Approach, December 2005

1612 Jack Mintz and Alfons J. Weichenrieder, Taxation and the Financial Structure of German Outbound FDI, December 2005

1613 Rosanne Altshuler and Harry Grubert, The Three Parties in the Race to the Bottom: Host Governments, Home Governments and Multinational Companies, December 2005

1614 Chi-Yung (Eric) Ng and John Whalley, Visas and Work Permits: Possible Global Negotiating Initiatives, December 2005

1615 Jon H. Fiva, New Evidence on Fiscal Decentralization and the Size of Government, December 2005

1616 Andzelika Lorentowicz, Dalia Marin and Alexander Raubold, Is Human Capital Losing from Outsourcing? Evidence for Austria and Poland, December 2005

1617 Aleksander Berentsen, Gabriele Camera and Christopher Waller, Money, Credit and Banking, December 2005

1618 Egil Matsen, Tommy Sveen and Ragnar Torvik, Savers, Spenders and Fiscal Policy in a Small Open Economy, December 2005

1619 Laszlo Goerke and Markus Pannenberg, Severance Pay and the Shadow of the Law: Evidence for West Germany, December 2005 
1620 Michael Hoel, Concerns for Equity and the Optimal Co-Payments for Publicly Provided Health Care, December 2005

1621 Edward Castronova, On the Research Value of Large Games: Natural Experiments in Norrath and Camelot, December 2005

1622 Annette Alstadsæter, Ann-Sofie Kolm and Birthe Larsen, Tax Effects, Search Unemployment, and the Choice of Educational Type, December 2005

1623 Vesa Kanniainen, Seppo Kari and Jouko Ylä-Liedenpohja, Nordic Dual Income Taxation of Entrepreneurs, December 2005

1624 Lars-Erik Borge and Linn Renée Naper, Efficiency Potential and Efficiency Variation in Norwegian Lower Secondary Schools, December 2005

1625 Sam Bucovetsky and Andreas Haufler, Tax Competition when Firms Choose their Organizational Form: Should Tax Loopholes for Multinationals be Closed?, December 2005

1626 Silke Uebelmesser, To go or not to go: Emigration from Germany, December 2005

1627 Geir Haakon Bjertnæs, Income Taxation, Tuition Subsidies, and Choice of Occupation: Implications for Production Efficiency, December 2005

1628 Justina A. V. Fischer, Do Institutions of Direct Democracy Tame the Leviathan? Swiss Evidence on the Structure of Expenditure for Public Education, December 2005

1629 Torberg Falch and Bjarne Strøm, Wage Bargaining and Political Strength in the Public Sector, December 2005

1630 Hartmut Egger, Peter Egger, Josef Falkinger and Volker Grossmann, International Capital Market Integration, Educational Choice and Economic Growth, December 2005

1631 Alexander Haupt, The Evolution of Public Spending on Higher Education in a Democracy, December 2005

1632 Alessandro Cigno, The Political Economy of Intergenerational Cooperation, December 2005

1633 Michiel Evers, Ruud A. de Mooij and Daniel J. van Vuuren, What Explains the Variation in Estimates of Labour Supply Elasticities?, December 2005

1634 Matthias Wrede, Health Values, Preference Inconsistency, and Insurance Demand, December 2005

1635 Hans Jarle Kind, Marko Koethenbuerger and Guttorm Schjelderup, Do Consumers Buy Less of a Taxed Good?, December 2005

1636 Michael McBride and Stergios Skaperdas, Explaining Conflict in Low-Income Countries: Incomplete Contracting in the Shadow of the Future, December 2005 
1637 Alfons J. Weichenrieder and Oliver Busch, Artificial Time Inconsistency as a Remedy for the Race to the Bottom, December 2005

1638 Aleksander Berentsen and Christopher Waller, Optimal Stabilization Policy with Flexible Prices, December 2005

1639 Panu Poutvaara and Mikael Priks, Violent Groups and Police Tactics: Should Tear Gas Make Crime Preventers Cry?, December 2005

1640 Yin-Wong Cheung and Kon S. Lai, A Reappraisal of the Border Effect on Relative Price Volatility, January 2006

1641 Stefan Bach, Giacomo Corneo and Viktor Steiner, Top Incomes and Top Taxes in Germany, January 2006

1642 Johann K. Brunner and Susanne Pech, Optimum Taxation of Life Annuities, January 2006

1643 Naércio Aquino Menezes Filho, Marc-Andreas Muendler and Garey Ramey, The Structure of Worker Compensation in Brazil, with a Comparison to France and the United States, January 2006

1644 Konstantinos Angelopoulos, Apostolis Philippopoulos and Vanghelis Vassilatos, RentSeeking Competition from State Coffers: A Calibrated DSGE Model of the Euro Area, January 2006

1645 Burkhard Heer and Bernd Suessmuth, The Savings-Inflation Puzzle, January 2006

1646 J. Stephen Ferris, Soo-Bin Park and Stanley L. Winer, Political Competition and Convergence to Fundamentals: With Application to the Political Business Cycle and the Size of Government, January 2006

1647 Yu-Fu Chen, Michael Funke and Kadri Männasoo, Extracting Leading Indicators of Bank Fragility from Market Prices - Estonia Focus, January 2006

1648 Panu Poutvaara, On Human Capital Formation with Exit Options: Comment and New Results, January 2006

1649 Anders Forslund, Nils Gottfries and Andreas Westermark, Real and Nominal Wage Adjustment in Open Economies, January 2006

1650 M. Hashem Pesaran, Davide Pettenuzzo and Allan G. Timmermann, Learning, Structural Instability and Present Value Calculations, January 2006

1651 Markku Lanne and Helmut Luetkepohl, Structural Vector Autoregressions with Nonnormal Residuals, January 2006

1652 Helge Berger, Jakob de Haan and Jan-Egbert Sturm, Does Money Matter in the ECB Strategy? New Evidence Based on ECB Communication, January 2006 
1653 Axel Dreher and Friedrich Schneider, Corruption and the Shadow Economy: An Empirical Analysis, January 2006

1654 Stefan Brandauer and Florian Englmaier, A Model of Strategic Delegation in Contests between Groups, January 2006

1655 Jan Zápal and Ondřej Schneider, What are their Words Worth? Political Plans and Economic Pains of Fiscal Consolidations in New EU Member States, January 2006

1656 Thiess Buettner, Sebastian Hauptmeier and Robert Schwager, Efficient Revenue Sharing and Upper Level Governments: Theory and Application to Germany, January 2006

1657 Daniel Haile, Abdolkarim Sadrieh and Harrie A. A. Verbon, Cross-Racial Envy and Underinvestment in South Africa, February 2006

1658 Frode Meland and Odd Rune Straume, Outsourcing in Contests, February 2006

1659 M. Hashem Pesaran and Ron Smith, Macroeconometric Modelling with a Global Perspective, February 2006

1660 Alexander F. Wagner and Friedrich Schneider, Satisfaction with Democracy and the Environment in Western Europe - a Panel Analysis, February 2006

1661 Ben J. Heijdra and Jenny E. Ligthart, Fiscal Policy, Monopolistic Competition, and Finite Lives, February 2006

1662 Ludger Woessmann, Public-Private Partnership and Schooling Outcomes across Countries, February 2006

1663 Topi Miettinen and Panu Poutvaara, Political Parties and Network Formation, February 2006

1664 Alessandro Cigno and Annalisa Luporini, Optimal Policy Towards Families with Different Amounts of Social Capital, in the Presence of Asymmetric Information and Stochastic Fertility, February 2006

1665 Samuel Muehlemann and Stefan C. Wolter, Regional Effects on Employer Provided Training: Evidence from Apprenticeship Training in Switzerland, February 2006

1666 Laszlo Goerke, Bureaucratic Corruption and Profit Tax Evasion, February 2006

1667 Ivo J. M. Arnold and Jan J. G. Lemmen, Inflation Expectations and Inflation Uncertainty in the Eurozone: Evidence from Survey Data, February 2006

1668 Hans Gersbach and Hans Haller, Voice and Bargaining Power, February 2006 